\title{
LI. Note on the relation between the mechanical equivalent of heat and the ohm
}

\section{L.B. Fletcher}

To cite this article: L.B. Fletcher (1880) LI. Note on the relation between the mechanical equivalent of heat and the ohm , Philosophical Magazine Series 5, 10:64, 436-437, DOI: $10.1080 / 14786448008626954$

To link to this article: http://dx.doi.org/10.1080/14786448008626954

曲 Published online: 08 May 2009.

Submit your article to this journal

Џll Article views: 4

Q View related articles $\square$ 
error due to this cause has in these later experiments been determined and allowed for. Five experiments were made, and the corresponding valnes of " $v$ " calculated from the results. These values are as follows:-

y.
$299 \cdot 9 \times 10^{8}$
$300 \cdot 3 \times 10^{8}$
$299 \cdot 4 \times 10^{8}$
$298.0 \times 10^{8}$
$299.9 \times 10^{8}$

Mean value . . $299.5 \times 10^{8}$.

LI. Note on the Relation between the Mechanical Equivalent of Heat and the Ohm. By L. B. Fletcher, Student in Physics, Johns Hopkins University*.

A SINGULAR error occurs in a paper, published in the A Philosophical Magazine (April and Mav 1880), by Dr. C. R. A. Wright. After remarking that Joule's value of the mechanical equivalent of heat, derived from experiments on the heat generated by a measured current in a wire of known resistance, is probably, when corrected for the error in the resistance-estimation due to superheating of the wire, from 1.5 to 2 per cent. higher than Joule's water-friction value, Dr. Wright goes on to say (p. 264) that:- "This difference between the two values is precisely that which would subsist did an error to an equal amount exist in the B.A. resistanceunit valuation: $i$. $e$. if the B.A. unit were 1.015 to $1 \cdot 020$ earth-quadrant per second instead of being exactly 1 earthquadrant per second, the value of J deduced from Joule's 1867 experiments would be 1.015 to 1.020 times the true value; for it is calculated by the formula

$$
J=\frac{\mathrm{C}^{2} \mathrm{R} t}{\mathrm{H}}
$$

where $\mathrm{C}$ is the current, $\mathrm{R}$ the resistance, $t$ the time, and $\mathrm{H}$ the heat evolved." This statement is evidently incorrect; for if the ohm is really 1.02 earth-quadrant per second, and was assumed by Joule to be exactly 1.00 earth-quadrant per second, Joule's value for the resistance of his wire, and consequently his value for $\mathrm{J}$ obtained by this method, must be 2 per cent. too small.

* Communicated by the Author. 
The fact, therefore, that Joule's value of $J$ obtained by this method is too large (assnming his water-friction value to be correct), points to the conclusion that the ohm is really smaller than it was intended to be, in accordance with the results of Rowland ${ }^{*}$ and Lorenz $\dagger$, and in direct contradiction to that of Kohlrausch. As the erroneous statement of Dr. Wright has apparently been confirmed by a redetermination of $J$, recently communicated by him to the Physical Society, and has, further, been given wide publicity by a reference in the address of Prof. W. Grylls Adams before the British Association, I am unwilling to allow it to pass any longer unchallenged. I bave been engaged for the greater part of a year in a redetermination of $J$ by the electrical method, avoiding the error due to superheating; and the results so far obtained confirm the supposition that the ohm is smaller than 1 earth-quadrant per second, although considerable time must elapse before I can publish the exact amount of its error.

Baltimore, November 8, 1880.

LII. On Action at a Distance. By WAlter R. Browne, M.A., M. Inst. C. E., late Fellow of Trinity College, Cambridge $\ddagger$.

$7 \mathrm{HE}$ object of this paper is partly historical, partly critical. 1 In discussing what is called "Action at a Distance," the statement is frequently made that Newton was of opinion that "nobody who possessed a competent faculty of thinking" could possibly imagine such a thing to exist. The writer wishes, first, to show historically that this is by no means an accurate representation of Newton's views, and, secondly, to consider critically whether the repudiation of "action at a distance," which is now certainly common, is, after all, justified by the facts of the universe.

In the first place, Newton's words, contained in the Third Letter to Bentley, are as follows :- "That gravity should be innate, inherent, and essential to matter, so that one body may act on another body at a distance through a vacuum, without the mediation of any thing else by and through which their action and force may be conveyed from one to the other, is to me so great an absurdity that I believe no man who has in philosophical matters a competent faculty of thinking can ever fall into it. Gravity must be caused by an agent acting constantly according to fixed laws; but whether this agent be

* Am. Jour. Sci. and Arts, April 1878 (vol. xv.).

+ Pogg. Ann. Bd. cxlix. (1873) p. 251.

$\ddagger$ Communicated by the Physical Society, having been read at the Meeting on November 13.

Plil. Mag. S. 5. Vol. 10. No. 64. Dec. 1880. 